\section{Geburtstage}

(Oktober bis Dezember 2013)

\section{Jahre}

n Prof. Dr. Heide M. Pfarr Kassel

- Regine Wessel-Meessen Richterin am SG i.R. Freiburg

\section{Jahre}

Dr. Utta Kaiser-Plessow Richterin am FG i.R. Köln

- Prof. Dr. Gisela Zenz Universitätsprofessorin Frankfurt am Main

\section{Jahre}

- Dr. Melitta Büchner-Schöpf Ministerialdirigentin a.D.

Karlsruhe

- Ursula Lüling

Rechtsanwältin i. R.

Stuttgart

\section{Jahre}

- Edith Endrös-Baum

Rechtsanwältin

Stockdorf

\section{Verstorben}

(Oktober bis Dezember 2013)

- Angelika Grebner

Rechtsanwältin/Mediatorin

BAFM

Mainz

im 54. Lebensjahr

- Gisela Koziczinski

Rechtsanwältin

Ludwigshafen

im 61. Lebensjahr

Dr. Elisabeth Schwarz

Regierungsdirektorin i.R.

Hamburg

im 88. Lebensjahr

\title{
NZFam - Neue Zeitschrift für Familienrecht
}

Der Verlag C.H. Beck hat sein familienrechtliches Programm umgestellt. Anstelle von „FamFR - Familienrecht und Familienverfahrensrecht“ und die „FPR - Familie, Partnerschaft und Recht“ gibt es nun die „NZFam - Neue Zeitschrift für Familienrecht“ mit Datenbankzugriff. Zu den Herausgeberinnen gehören u.a. Direktorin des Amtsgerichts Brigitte Meyer-Wehage (Vorsitzende der djb-Kommission Zivil-, Familien- und Erbrecht, Recht anderer Lebensgemeinschaften), Rechtsanwältin und Senatorin a.D. Dr. Lore Maria Peschel-Gutzeit (Ehrenpräsidentin des djb) sowie Rechtsanwältin und Notarin Jutta Wagner (Präsidentin des djb von 2005 bis 2011).

Der Preis für das Jahresabo beträgt 199 Euro, für Studenten und Referendare 149 Euro. NJW-Bezieher erhalten einen Vorzugspreis von 179 Euro. Ein dreimonatiges kostenloses Schnupper-Abo gibt es unter www.beck-shop.de/13345709.

\section{djb wechselt von Deutscher Bank zur GLS}

Dem Wunsch der Mitglieder entsprechend, hat der djb seine Bankverbindung gewechselt: Von der Deutschen Bank zur GLS. Grund ist insbesondere, dass trotz der intensiven und jahrelangen Diskussionen über die Erhöhung des Anteils von Frauen in Führungspositionen, Vorständen und Aufsichtsräten sich im Vorstand der Deutschen Bank auch heute noch keine Frau findet. Im 20-köpfigen Aufsichtsrat gibt es auf Anteilseignerseite drei Frauen (von zehn), auf Arbeitnehmerseite sind es vier (von ebenfalls zehn).

\section{Die neuen Kontodaten:}

Deutscher Juristinnenbund e.V. (djb)

IBAN: DE66 4306096711564928 o0

BIC: GENODEM1GLS

Konto-Nr.: 1156492800

BLZ 43060967

GLS Gemeinschaftsbank eG 